EPiC Series in Language and Linguistics
Volume 3, 2018, Pages 40-46
LSP in Multi-disciplinary contexts of
Teaching and Research. Papers from the
16th International AELFE Conference

\title{
The growth of EMI tertiary programs in Spain: novel approaches to developing linguistic competence in instructors
}

\author{
Laura V. Fielden Burns ${ }^{1}$, Mercedes Rico García ${ }^{2}$, Remedios Hernández \\ Linares $^{3}$ \\ ${ }^{1}$ Departamento de Didáctica, Universidad de Extremadura \\ 10003 Cáceres (Spain); lvfielden@unex.es \\ ${ }^{2}$ Departamento de Filología Inglesa, Universidad de Extremadura \\ 06800 Mérida (Spain); mricogar@unex.es \\ ${ }^{3}$ Departamento de Economía Financiera y Contabilidad, Universidad de Extremadura 06800 Mérida \\ (Spain); remedioshl@unex.es
}

\begin{abstract}
As Dearden notes (2015), teaching tertiary programs in English is a growing phenomenon, and the number of universities incorporating these into their program offerings have risen substantially in the last decade. This may be due to the rise of the importance of internationalization (Morell, Alesón, Bell, Escabias, Palazón \& Martínez, 2014). Bologna is also often credited for this change (Kirkpatrick, 2016). However, as the case in Italian public universities show, converting whole programs to English as a matter of course may meet with resistance from faculty and students, and perhaps for good reasons. This paper explores the rise in EMI tertiary programs in Spain and from a European context, and presents approaches to develop linguistic competence in instructors. It seeks to understand how this up and coming trend may affect teaching English at this level. How will EMI instructors become more focused on teaching language as well as their content area?
\end{abstract}

Keywords: EMI, tertiary programs, Spain, EU

\section{Contextualization}

In European countries university programs with degrees offered in English as a foreign language have increased by nearly $1000 \%$ since 2002 (Wächter \& Maiworm, 2014). This may be due to the rise 
of the importance of internationalization (Morell, Alesón, Bell, Escabias, Palazón \& Martínez, 2014) as universities seek to expand their student base and enrich and diversify their programs. The Adaptation to the European Higher Education Area (EHEA), often known as the Bologna Process, is also often credited for this change (Kirkpatrick, 2016), given its emphasis on plurilingualism and international mobility.

The nomenclature surrounding the phenomenon of teaching content programs in English has not always been consistent, but given present research we can refer to the majority of these types of programs as English as Medium of Instruction programs, which Dearden defines as:

The use of the English language to teach academic subjects in countries or jurisdictions where the first language (L1) of the majority of the population is not English (p. 2).

This definition does not differentiate between subjects taught only in English or partially in English, which is useful for our purposes here.

Spain has continued the EMI trend, firstly in primary and secondary education through the rise of CLIL programs, which began in the 1990's with the Ministry of Education's pilot programs in partnership with the British Council. Tertiary education followed suit, as Ramos García showed (2012) when she compiled research on Spanish universities with programs in languages not native to the peninsula (almost all of these were English), and found that the number of universities incorporating multilingual undergraduate programs was 33 of the 77 (public and private) universities, about $42 \%$. In Spain, these degree programs have a variety of ways of doing EMI: "bilingual" programs which tend to offer 50\% of a degree in English, programs which offer English and Spanish versions of the same degree, and finally, programs that have degrees only on offer in English (Ramos García, p. 3). In general there is a wider range of degrees in private universities than in public ones (p. 9), which means that private universities are offering on the whole more EMI programs, despite our European mandate.

Why have public universities lagged behind? Perhaps due to an extrinsic, economic pressure to internationalize, EMI programs are often born from a 'top-down' approach, according to Dearden, where policy makers and education managers are the ones promoting these changes (p. 2), an approach admittedly easier to manage in the private sector. In the public system, such decisions may need more time to come through. What is more, extrinsic pressure to adopt EMI programs may not be taken so simple to initiate in the public sphere. On the one hand, there could be a tug-of-war from the regional and national institutions, such as on determining who will financially support ambitious initiatives. On the other, the rigidity and necessary weight of a civil servant-based system may sometimes make change problematic, where established professors balk at being made to teach in a foreign language, as exemplified by the Italian university professor, Emilio Matricciani. Matricciani began an "Appeal for Freedom of Teaching" petition along with 285 other instructors to protest their being made to teach in English, stating "it is wrong in principle for an Italian public university to force students and staff to use English" (Coughlan, 2012).

\section{Approaches to developing linguistic competence in instructors}

One common complaint among EMI instructors is that teaching in a foreign language results in a loss of control over the content of one's class, or a simple watering down of the same, to the detriment 
of students. Some students may feel the instructors language level is not high enough to transmit the information effectively or teachers may feel that students cannot manage the content in English in general, or that mixed-level groups make this difficult (Barrios, López-Guitérrez, Lechuga, 2016). Morell, Alesón, Bell, Escabias, Palazón \& Martínez (2014) found that $32 \%$ of teachers queried in a university-wide study at the University of Alicante, ( $N=828$ teachers, $N=2,257$ students) did not feel confident enough in their English language skills to consider teaching in that language, and that students felt even less confident in their abilities in English when asked about taking EMI courses in general. Interestingly, even though the majority of lecturers indicated that EMI courses should be promoted, they also said that they were not willing to teach such courses themselves $(76 \%$ answered negatively), though many also indicated that they might consider it if specific training were available to support them. This led the authors to conclude that "the main issue in the implementation of EMI courses is to know the reasons for which teachers are reluctant to join the programme, and the possible motivating schemes that could be implemented" (p. 7).

More Spanish public universities have boarded the EMI train in the last five years, so it is becoming more urgent to examine ways to support teachers in these programs. One of the most salient concerns from EMI instructors at the tertiary level is linguistic competence, which may be vital to their motivation for going on to teach such courses and thus contribute to the internationalization of their departments and universities. For this reason, this paper seeks to address the following question:

1. What are up and coming EMI programs doing to address the challenges of EMI offers, in particular how to support the linguistic development of traditionally content-orientated instructors in EMI courses?

\section{Internationalization through EMI at the Mérida Campus (UEx)}

The University of Extremadura had no multilingual programs in 2012, and was not one of the universities listed in Ramos García's 2012 study, but since then has developed bilingual programs in primary education, computer engineering, economics and science. More bilingual programs are being planned, and the university is approaching the linguistic development of its future EMI instructors in novel ways. We will focus on one particular case, that of the Merida Campus and its efforts to prepare future EMI instructors for teaching their courses in English through a Teaching Innovation Project. In accordance with the University of Extremadura's internationalization objectives, the Mérida campus took into its Quality Objectives the specific goal of improving English language education and student and scholar mobility, so this was well within the scope of the campus' established goals.

\subsection{Participants}

One of the most interesting characteristics of the Mérida Campus project is that the motivation to internationalize their courses comes from the 17 instructors themselves, so this is a rather organic development begun from the ground, the opposite to what Dearden found to be an obstacle to EMI programs in other cases. Instructors from a variety of fields principally related to engineering came together two years ago in a Teaching Innovation Project to develop strategies and actions that would contribute to the internationalization of their campus. In their degree programs only one course was taught in English, and they shared an awareness that this was insufficient for students to gain the intercultural and linguistic knowledge needed to be competitive in the job market. 


\subsection{Proposal: Aims and Methodology}

To cover the objectives, the project had two principal areas of work: 1. Continuing education in English as a foreign language, and 2. Fomenting internationalization in the Mérida Campus through mobility programs, for students and professors. Specifically, the instructors committed to: A. Improving their English, working specifically towards a $\mathrm{C} 1$ certification level, B. Introducing didactic material in English into specific subjects, with the aim of introducing the foreign language (in this case, English) transversal competency into these courses, C. Fomenting motivation and creating tools and resources that will aid instructors to begin a bilingual program plan, in at least one of the undergraduate degrees offered at the Mérida Campus, in the 2017-2018 academic year.

We will be examining the first area in more detail here, that of linguistic improvement. The Innovative Teaching Project for Internationalization of the Mérida Campus looked at several ways to develop instructors' linguistic competence in English, undertaking the following specific actions for improving their English and their future English teaching.

\subsection{Description of the Linguistic Proposal}

\section{General English language classes}

Part of the project consisted in improving instructors' English levels as well as familiarizing them with the various certification options available. Throughout the project instructors took general language classes to work towards their goal of obtaining a $\mathrm{C} 1$ certification. After the first year, 5 instructors had received their $\mathrm{C} 1$ certification, and at the end of the second 2 more achieved this goal.

\section{Methodology workshops}

Workshops aimed at teaching principally CLIL methodology, but also other areas and strategies for foreign language teaching (scaffolding, project-based learning, etc) initiated these future EMI instructors into their dual roles as both content instructors and to some degree, language instructors in future EMI courses. All of these workshops were delivered in English, and the following is a sample list of workshops given:

The first four workshops focused on applied linguistics tools, strategies and methodologies. These were the following:

-Didactic Tools In English For Science \& Technology Course Teaching At University

This was a first contact workshop for getting to know different language teaching tools and strategies, such as scaffolding, etc.

\section{-Teaching with CLIL I and II}

These workshops focused on how to teach through the CLIL methodology, introducing participants to its principal areas, which are: 


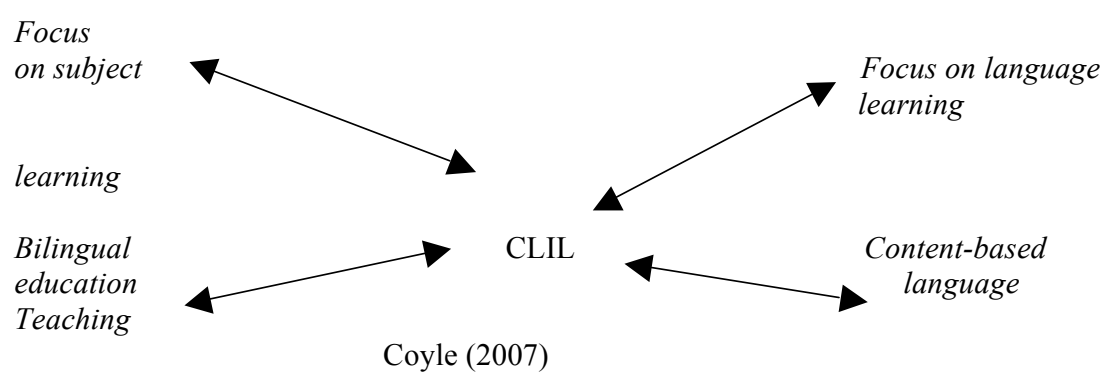

It is important to note that a CLIL lesson is not a language lesson or a subject lesson transmitted in a foreign language, but a methodology where knowledge is built as students are using the language while learning to use the language. Although CLIL may be the best-fit methodology for language teaching and learning in a multilingual Europe, the lack of teacher training programs to prepare both language and subject teachers for CLIL teaching remains unsolved. To cope with this problem, the choice of media, skills and inputs to cover the teaching topic offer a clear framework for task design. The need for scaffolding to help students cope with foreign language input of all sorts is also essential. The quantity and intensity of scaffolding can be reduced as students' language skills advance.

-Project-based Learning For English For Specific Purposes Students

This workshop focused on Project Based Learning as an interesting approach to an EMI class being taught through CLIL and communicative language.

The last two workshops focused on language terminology for teaching English, in particular that needed for translating and improving their syllabi:

-English Language For Course Syllabi

-Improving English For Specific Purposes' Course Syllabi

\section{Material translation}

Course materials were translated by the instructors into English for use within their future EMI courses and using CLIL methodology.

\section{Syllabus translation}

Each instructor translated her or his own syllabus after two workshops designed to work on syllabus and academic vocabulary for this purpose. What is more, syllabus identification in English served to reflect and communicate the instructor's course design under the new CLIL methodology (goals, organization, evaluation, expectations, requirements, etc.). These syllabi were reviewed and corrected in follow-up phases of this action.

\section{Practice sessions in English with peers}

Instructors taught one mini-session of their course in English to their peers as a first experience in teaching in English. Some of the deficiencies found are shown in table 1, below. 


\begin{tabular}{|l|l|}
\hline Main Setbacks & Proposed Solutions \\
\hline $\begin{array}{l}\text { Recognition of the importance of improving } \\
\text { their proficiency level in English }\end{array}$ & Continuing education support \\
\hline $\begin{array}{l}\text { Lack of exemplification/practice in their } \\
\text { teaching proposals (oral discussions and } \\
\text { debates, and for setting academic written } \\
\text { assignments in English) }\end{array}$ & $\begin{array}{l}\text { Assisted structured materials development } \\
\text { Tasks development aimed at both discipline } \\
\text { related content teaching and English } \\
\text { development) }\end{array}$ \\
\hline $\begin{array}{l}\text { Task Design - Scaffolding- (no relevant } \\
\text { changes to their methodological approach when } \\
\text { teaching through the medium of English) }\end{array}$ & $\begin{array}{l}\text { Video recording of instructors to self- } \\
\text { reflect, analyze methodological approaches } \\
\text { and discuss strategies for improvement. } \\
\text { Creation of a repository of textual and } \\
\text { multimedia resources }\end{array}$ \\
\hline $\begin{array}{l}\text { Language: lack of connectors/speech unity } \\
\text { and coherence. Academic Versus Colloquial } \\
\text { English }\end{array}$ & $\begin{array}{l}\text { Formative observation in class; language } \\
\text { specialists provide formative feedback by } \\
\text { means of rubrics }\end{array}$ \\
\hline
\end{tabular}

Table 1. Setbacks and Solutions

\section{Practice sessions in English in instructors' present courses}

Finally, each instructor conducted an experimental English session during one class in his or her respective course. The goal of this session was two-fold; to gain practice teaching their content in English, and to gauge students' opinions on the experience.

\section{Conclusions}

The first conclusion drawn concerns the foundations of EMI in higher education where the most common reasons for introducing it are internationalization policies and students/scholars' mobility. Another underlying reason points to students' need to access scientific publications and employability.

Though language teaching skills are not often required to carry out EMI instruction, instructors have clearly demonstrated, in the studies aforementioned, low confidence in their language skills and the desire and need to have more linguistic training. What is more, the formulation of clear language objectives is necessary to reach the full potential of EMI to design effective teaching models. Without these language considerations there would be no differences among EMI courses designed in different languages. In this context, research is needed to confirm whether or not language learning takes place in present EMI courses.

Specifically our project was focused on the identification of strategies and approaches to develop linguistic competence in EMI instructors. In this sense, all instructors' syllabi were translated into English, tasks were designed for each area when teaching in English using the CLIL methodology, and practice teaching specific content in English with their peers and actual students was carried out. What is more, seven of the 17 group members obtained their $\mathrm{C} 1$ level certification, and the rest advanced considerably towards this goal. 


\section{References}

Barrios, E., López-Gutiérrez, A., \& Lechuga, C. (2016). Facing challenges in English Medium Instruction through engaging in an innovation project.

Coughlan, S. (2012, May 16). Italian university switches to English. BBC News. Retrieved from: http://www.bbc.com/news/business-17958520.

Coyle, D A (2007). A vision for CLIL: past, present and future action. Handout from CLIL Conference, March 2nd, Anglo European School, Bishop's Stortford, UK 2007

Dearden, J. (2015). English as a medium of instruction- a growing phenomenon.

British Council. $\quad$ https://www.britishcouncil.org/sites/default/files/e484 emi cover option 3 final web.pdf

Kirkpatrick, R. (2016). English Language Education Policy in the Middle East and North Africa. Cham, Switzerland: Springer International Publishing.

Morell, T., Alesón-Carbonell, M., Bell, D., Escabias Lloret, P., Palazón Speckens, M,. \& Martínez-

Espinosa, R.M. (2014). English as the medium of instruction: A response to internationalization. 2014 XII Jornadas Redes. http://rua.ua.es/dspace/handle/10045/42431.

Wächter, B., \& Maiworm, F. (2014). English-Taught Programmes in European Higher Education. The State of Play in 2014. Bonn: Lemmens. 